\title{
FIRST USE OF STEREOLOGY TO QUANTIFY THE SURVIVAL OF FAT AUTOGRAFTS
}

\author{
EDUARDO SERNA CUÉLlAR ${ }^{1}$ AND LUIS SANTAMARÍA SOLÍS ${ }^{2}$ \\ ${ }^{1}$ Department of Plastic Surgery, La Paz University Hospital, Autonomous University of Madrid, Spain; \\ ${ }^{2}$ Department of Morphology, School of Medicine, Autonomous University of Madrid, Spain \\ e-mail: eduardoserna7@msn.com \\ (Accepted October 14, 2005)
}

\begin{abstract}
It is not usual to perform quantitative analyses on surgical materials. Rather, they are evaluated clinically, through qualitative methods, and if quantitation is done, it is on a 2-dimensional basis. In this study, the long-term survival of fat autografts (FAG) in 40 subjects with facial soft tissue defects is quantified. An adipose tissue preparation from the abdomen obtained through liposuction and centrifugation is injected subcutaneously. Approximately 14 months later, the treated area is biopsied. Extensive computer-based histological analyses were performed using the stereological method in order to directly obtain three parameters: volume fraction of adipocytes in the fat tissue $\left(\mathrm{V}_{\mathrm{V}}\right)$, density (number per volume) of adipocytes in the fat tissue $\left(\mathrm{N}_{\mathrm{V}}\right)$, and the mean cell volume of adipocytes (VA) in each tissue sample. A set of equations based on these three quantitative parameters is produced for evaluation of the volumetric survival fraction (VSF) of FAG. The presented data evidenced a $66 \%$ survival fraction at the 14-month follow-up. In routine practice, it would be sufficient to perform this volumetric analysis on the injected and biopsied fat samples to know what fraction of the FAG has survived. This is an objective method for quantifying FAG survival and will allow a standardized comparison between different research series and authors.
\end{abstract}

Keywords: facial defects, fat autografts, quantitation, stereology, survival.

\section{INTRODUCTION}

Over the past 110 years (Neuber, 1893), fat autografts (FAG) have been used in reconstructive surgery (ASPRS, 1998) to combat the high prevalence of facial soft tissue defects following surgical procedures or trauma, and to correct the aging face in cosmetic surgery (Chajchir and Benzaquen, 1989; Wilkinson, 1994). The use of FAG is controversial as resorption has been extensively observed (Ellenbogen, 2000) and documented (Billings and May, 1989), and because of the absence of an accurate and objective method to evaluate FAG survival (Bircoll, 1987).

A few authors have ventured to evaluate FAG survival, using diverse methods (Gormley and Eremia, 1990; Horl et al., 1991). The published survival rates of FAG are divergent, ranging from 10 to $90 \%$ (Matsudo and Toledo, 1988; Nguyen et al., 1990; Pinski and Roenigk, 1992). The following questions remain unanswered (Goldwyn, 1988): Does the fat graft survive on the face? How long and to what extent? How can it be evaluated? What is the survival rate of FAG? Is it enough to achieve effective soft tissue augmentation? Many reports concerning the success of FAG in humans are widely subjective or semiquantitative at best. Additional studies, clinical or basic, are required before the value of this technique can be evaluated (Boyce et al., 1994). Outcome studies of aesthetic procedures, like FAG, should be evaluated by quantitative means, with different observers and long-term follow-ups, to bring plastic surgery back into scientific, medical and academic circles (Castro Ferreira, 2003) and plastic surgeons closer to practice of "evidence-based medicine".

The aim of this study was to quantify FAG survival after a one-year follow-up by means of a stereological method. The measured survival characteristics were compared with results from other authors who had used different evaluation methods.

\section{MATERIAL AND METHODS}

\section{PATIENTS AND THE SURGICAL PROCEDURE}

40 patients were selected fulfilling strict inclusion criteria. All of them followed the same clinical protocol: clinical history, general physical examination, pre- 
operative and postoperative clinical photographs in five standard projections, complete preoperative and preanaesthesia evaluation, intraoperative sedation and local infiltrative anaesthesia (Klein, 1987). The same operation was performed by the same surgeon at the Ambulatory Surgery Unit, following the three surgical steps of the Facial Contouring Lipostructure Technique described by Coleman in 1997 (Fig. 1). From each patient, a sample of aspirated fat (AF) was taken and its volume measured by a graduated syringe (clinical volume of aspirated fat, AV). Then, the $\mathrm{AF}$ was centrifuged at $3,000 \mathrm{rpm}$ for $2 \mathrm{~min}$ in order to eliminate free fatty acids, blood, serum, anaesthesia solution and tissue debris, which resulted in a sample of centrifuged fat (CF), and its volume was determined (CV). A fraction of this volume (injected volume, IV) was finally injected into the facial defect and registered as well. The mean injected volume was $26 \pm 7 \mathrm{~cm}^{3}$, in parallel to that used by other authors (Nguyen et al., 1990). Antibiotic, anti-inflammatory and analgesic postoperative treatment was given and a periodic follow-up at the outpatient clinic was carried out.

Biopsies of the fat autografts $(\mathrm{BF})$ were performed with a $2 \mathrm{~mm}$ diameter Acuderm ${ }^{\circledR}$ punch at the 14 month follow-up. Each fat sample was fixed in a $10 \%$ formalin fixation, sliced in isotropic uniform randomized blocks (Gundersen et al., 1988) and paraffin embedded. The specimens were then serially cut into $10 \mu \mathrm{m}$ thick sections and stained with haematoxylin-eosin.

\section{STEREOLOGICAL ANALYSIS}

Stereological quantification was performed on the processed samples of aspirated, centrifuged and biopsied fat for each case, with the Stereologic CAST Grid System ${ }^{\circledR}$. (Stereologic Software Package GRID ${ }^{\circledR}$, Interactivision, Silkeborg, Denmark) This program comands automatic XY displacements of the microscope stage, allowing the systematic randomized sampling of tissue microscopical fields. The software program generates point grids, disectors and nucleators, superimposed on the tissue samples visualized on a monitor. The three stereological parameters measured directly on the fat tissue samples were: the volume fraction of adipocytes in the fat tissue $\left(\mathrm{V}_{\mathrm{V}}\right)$, the numerical density of adipocytes in the fat tissue $\left(\mathrm{N}_{\mathrm{V}}\right)$ and the mean cell volume of adipocytes (VA).
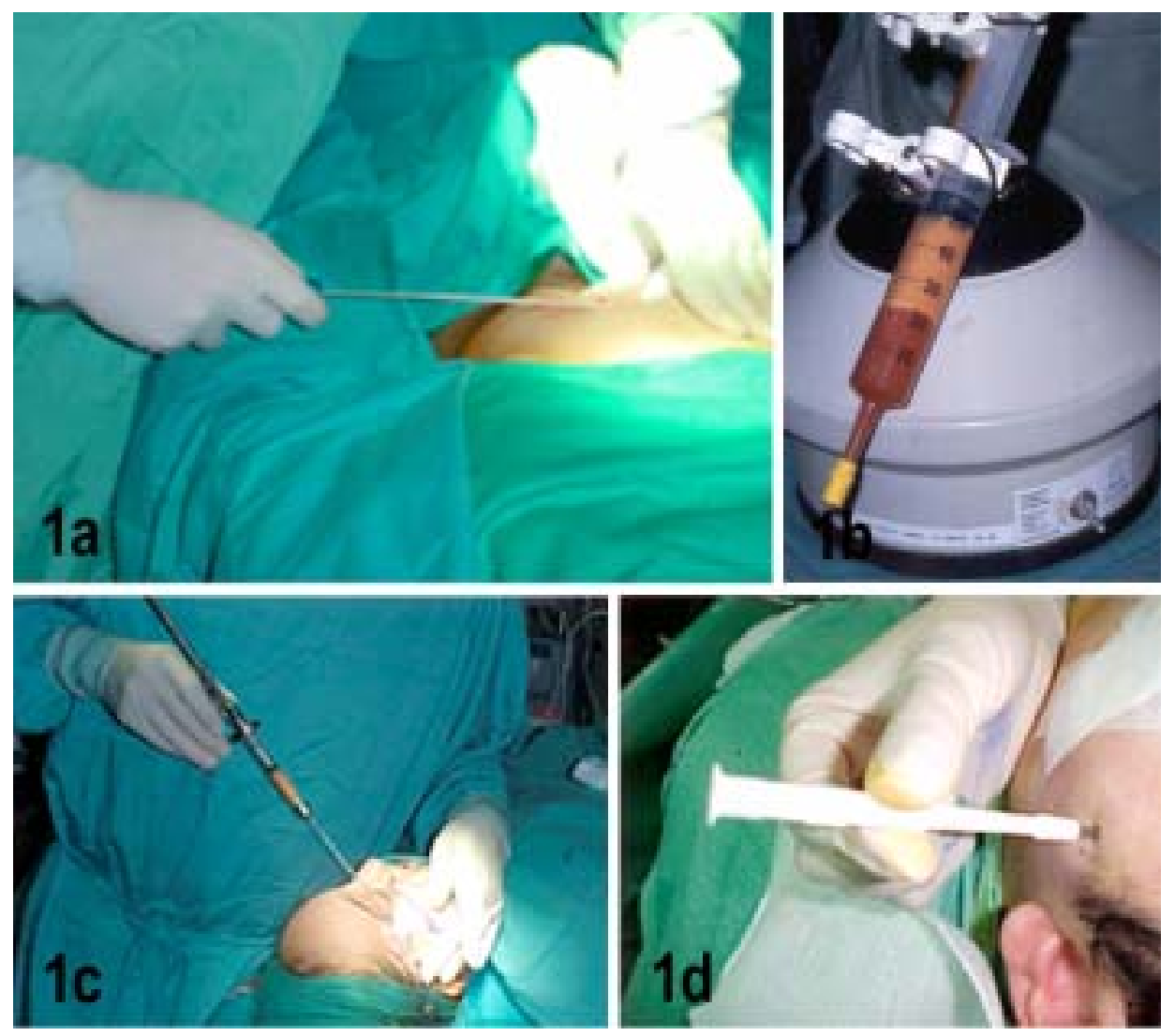

Fig. 1. Steps in the surgical procedure. 1a. Abdominal tumescent liposuction. 1b. Centrifugation of the lipoaspirate. 1c. Lipoinjection into the facial defect. 1d. Fat biopsy from the lipoinjected area at the 14-month follow-up. 


\section{Calculation of the volume fraction of adipocytes in the fat tissue $\left(V_{V}\right)$}

A systematic randomized sampling of microscopical fields was made at $4 \mathrm{x}$ magnification in each fat tissue section and a 25-point grid was super-imposed on each microscopical field (number of fields, NF: 12-30). Such sampling does not include all reference (fat) tissue, so only grid points lying in the fat tissue were counted. Points of the grid hitting the adipocytes satisfying the morphological viability criteria (integrity of plasmatic membrane, polygonal cellular morphology, normal cellular diameter, fusiform morphology and peripheral location of the nucleus, lobular organization of adipose tissue) were registered as Pad. The total number of points hitting viable adipocytes was registered as PadTot. $V_{V}$ expressed as a percentage is obtained as the ratio between PadTot and the total number of points superimposed (Pgrid $\times N F$ ):

$$
\mathrm{V}_{\mathrm{V}}(\%)=100 \times \text { PadTot } /(\text { Pgrid } \times \mathrm{NF}) .
$$

\section{Calculation of the numerical density of adipocytes in the fat tissue $\left(\mathrm{N}_{\mathrm{V}}\right)$}

The relative number of adipocytes was calculated by the optical disector principle (Gundersen, 1986; Mendis-Handagama, 1992; Mayhew and Gundersen, 1996). Disectors were generated as succesive focal planes inside a thick segment of adipose tissue (optical disector). Measurement along the Z-axis of the microscope was performed with a $0.5 \mu \mathrm{m}$ precision microcator (Transreut ${ }^{\circledR}$, Germany) connected to the stage. A 100x objective was used with immersion oil (numerical aperture 1.4) to reach a $1,200 \times$ final magnification, insuring that Z-direction displacements of $5 \mu \mathrm{m}$ were true movements of the focal plane inside the thick section of tissue.

In the $10 \mu \mathrm{m}$ thick adipose tissue sections, microscopical fields were selected by systematic randomized sampling (Cruz-Orive, 1987). An unbiased counting frame of the disector of a known area (Ad) was superimposed on each microscopical field captured by the camera and projected on the monitor, i.e., the number of disectors $(\mathrm{Nd})$ was equal to the number of fields $(\mathrm{Nd}=\mathrm{NF} \cong 40)$. The disector volume $(\mathrm{Vd})$ is equal to the product of the known disector frame area (Ad) and the disector height (Hd), which is the distance between the focal planes $(\mathrm{D}=5 \mu \mathrm{m})$ : $\mathrm{Vd}=\mathrm{Ad} \times \mathrm{Hd}=1,312 \times 5=6,560 \mu \mathrm{m}^{3}$. Therefore, the total volume of tissue in which the number of adipocytes is counted will be: $\Sigma \mathrm{Vd}=\mathrm{Vd} \times \mathrm{Nd}=$ $6,560 \times 40=262,400 \mu \mathrm{m}^{3}$.
The number of adipocytes was counted assuming their nuclei as the counting unit (each corresponds to only one adipocyte). Only adipocytes within the unbiased counting disector frame and satisfying the Sterio rule were counted (Miles, 1978; Sterio, 1984; Mendis-Handagama, 1992). These are designed as Q', and the total number of adipocytes counted is $\Sigma Q^{-}$. Thus, the numerical density of adipocytes, expressed as the number of adipocytes per $\mathrm{mm}^{3}$ of tissue was:

$$
\mathrm{N}_{\mathrm{V}}=\Sigma \mathrm{Q}^{-} / \Sigma \mathrm{Vd} \text {. }
$$

\section{Calculation of the mean cell volume of adipocytes (VA)}

The mean cell volume of adipocytes was obtained following the nucleator method (Gundersen and Jensen, 1985; Jensen and Sundberg, 1986 Gundersen and Jensen, 1987;): At 20x magnification, a reference point is marked at the geometrical center of the adipocyte, through which the stereological program produces two perpendicular axes, intersecting the cellular membrane of the adipocyte at four points. These four intersections are marked, and the program estimates the volume of the structure (expressed in $\mu^{3}$ ) based on the formula: $\mathrm{VA}=4 / 3 \pi 1_{\mathrm{o}}{ }^{3}$, considering $1_{\mathrm{o}}$ as the mean length of the segments between the reference point and membrane intersection point.

The mean cellular volume of the adipocytes (VA) is calculated as the total volume of the adipocytes ( $\Sigma \mathrm{VA}$ ) sampled for the measurement divided by the total number of sampled adipocytes (n):

$$
\mathrm{VA}\left(\mu \mathrm{m}^{3}\right)=\Sigma \mathrm{VA} / \mathrm{n} \text {. }
$$

\section{Estimation of the volumetric survival fraction (VSF) of the FAG}

As a portion of the clinical fat volumes are not really adipose tissue but fibro-connective tissue and as not all adipose tissue is viable and clinically effective, it is necessary to correct the clinical volumes of fat by the volume fraction of viable adipocytes of the fat tissue to obtain the effective volumes of fat (efV).

The effective volumes of aspirated (AefV), centrifuged (CefV) and injected fat (IefV), expressed in $\mu \mathrm{m}^{3}$, are obtained by multiplying their clinical volumes $(\mathrm{AV}, \mathrm{CV}, \mathrm{IV})$ by their respective volume fractions of the adipocytes in the fat tissue $\left(\mathrm{V}_{\mathrm{V}}\right)$ :

$$
\begin{gathered}
A \text { efV }=\mathrm{AV} \times \text { Aspirated fat } \mathrm{V}_{\mathrm{V}} / 100, \\
\mathrm{CefV}=\mathrm{CV} \times \text { Centrifuged fat } \mathrm{V}_{\mathrm{V}} / 100, \\
\mathrm{IefV}=\mathrm{IV} \times \text { Injected fat } \mathrm{V}_{\mathrm{V}} / 100
\end{gathered}
$$


In an analogous way, the effective volume of biopsied fat (BefV) will be:

$$
\text { BefV }=\mathrm{IV} \times \text { Biopsied fat } \mathrm{V}_{\mathrm{V}} / 100 \text {. }
$$

These effective volumes of fat allow us to obtain the absolute number of adipocytes (NA) in each sample of fat as its relative number per $\mathrm{mm}^{3}$ of adipose tissue $\left(\mathrm{N}_{\mathrm{v}}\right)$ :

$$
\begin{gathered}
\text { Aspirated NA }=\text { AefV } \times \text { Aspirated } \mathrm{N}_{\mathrm{V}} \times 10^{3}, \\
\text { Centrifuged NA }=\mathrm{CefV} \times \text { Centrifuged } \mathrm{N}_{\mathrm{V}} \times 10^{3}, \\
\text { Injected NA }=\mathrm{IefV} \times \text { Centrifuged } \mathrm{N}_{\mathrm{V}} \times 10^{3}, \\
\text { Biopsied NA }=\operatorname{BefV} \times \text { Biopsied } \mathrm{N}_{\mathrm{V}} \times 10^{3} .
\end{gathered}
$$

Finally, as our objective is to know how much of the injected volume of fat has survived over time, IefV is considered as the maximum volume of viable adipose tissue with the ability to survive, so we have to reference BefV to this volume. Thus, the volumetric survival fraction (VSF) of the FAG based on volume and expressed as a percentage is easily obtained as the ratio between the effective volume of the biopsied fat (final time) and the effective volume of the injected fat (initial time):

$$
\operatorname{VSF}(\%)=\mathrm{BefV} / \mathrm{IefV} \times 100 .
$$

\section{STATISTICAL ANALYSIS}

The SPSS.11 version (Statistical Product and Service Solutions ${ }^{\circledR}$ Inc. Chicago, IL, USA, 1995) was used, considering a significance level of $p<0.05$ for all values. Statistical analysis consisted of: a description of all clinical and stereological data as mean \pm standard deviation in their respective units; comparison of pairs of means with the Student's t-test for paired data of dependent samples, and the analysis of variance for one factor (ANOVA) and the Student-NewmanKeuls test to compare the variation of a stereological parameter in the groups defined by the type of fat.

\section{RESULTS}

29 patients were women (71\%) with a mean age of $37 \pm 17$ years (range: 8-68). Follow-up was completed in $100 \%$ of the patients, within an average period of $14 \pm 3$ months (range: 8-22). The clinical volumes of aspirated, centrifuged and injected fat were respectively: $1305 \pm 955,49 \pm 42$ and $26 \pm 7$ $\mathrm{cm}^{3}$. The effective volumes of aspirated, centrifuged, injected and biopsied fat were respectively: $47 \pm 40$ $5,46 \pm 40,24 \pm 6$ and $14 \pm 14 \mathrm{~cm}^{3}$. There were statistically significant differences between: the clinical and effective volumes of aspirated fat; the clinical volumes of aspirated, centrifuged and injected fat; and the effective volumes of centrifuged, injected and biopsied fat.

Global results of stereological parameters of the study and statistically significant differences between the types of fat are shown in Fig 2. The global volumetric survival fraction (VSF) was $66 \pm 25 \%$.

\section{DISCUSSION}

The preservation of histological features in fat biopsies after 14 months of grafting confirms the survival of auto-transplanted fat as stated by other authors (Peer and Walker, 1951; Mc Carthy, 1990). The mean value of VSF is high in relation to other rates published in the literature (Assadi and Haramis, 1993; Niechajevia and Sevcuk, 1994; Ersek et al., 1998). There is a remarkable difference between our $66 \%$ survival and the $90 \%$ survival reported by Coleman $(1995 ; 1997)$ and with the study of Guerrerosantos (2000) that employed the same surgical procedure. This could be explained either by the greater precision of our stereological method or because these authors used to repeat the fat injection several times in order to assure a better outcome. Nevertheless, the methods employed in these studies for monitoring the success of the grafting were rather subjective and difficult to standardize: such studies do not provide completely reliable quantitative data in order to arrive at any conclusions about FAG survival (Grazer and Klingbeil, 1980).

The results of the present study (volume fraction of adipocytes and VSF) are in line with those stated by other authors (Von Heimburg and Pallua, 2001) and indicate that there was a loss of more than onethird of the injected fat. This decrease of adipose tissue volume, together with the stability of the numeric density of adipocytes, might be due to a parallel decrease of their absolute number and their mean volume.

The stereological results suggest the loss of viable adipose tissue and its substitution by scarring fibrous tissue. This phenomenon explains the loss of effective filling of facial defects already evident before the 14month follow-up (Kononas et al., 1993). Thus, clinical correction is directly determined by the surviving adipose tissue (Smahel, 1986), while the scarring fibrous tissue does not contribute to augmenting the soft tissue volume causing the graft retraction (May, 1990; Carpaneda and Ribeiro, 1994). The resorption and retraction seem to be inherent and 

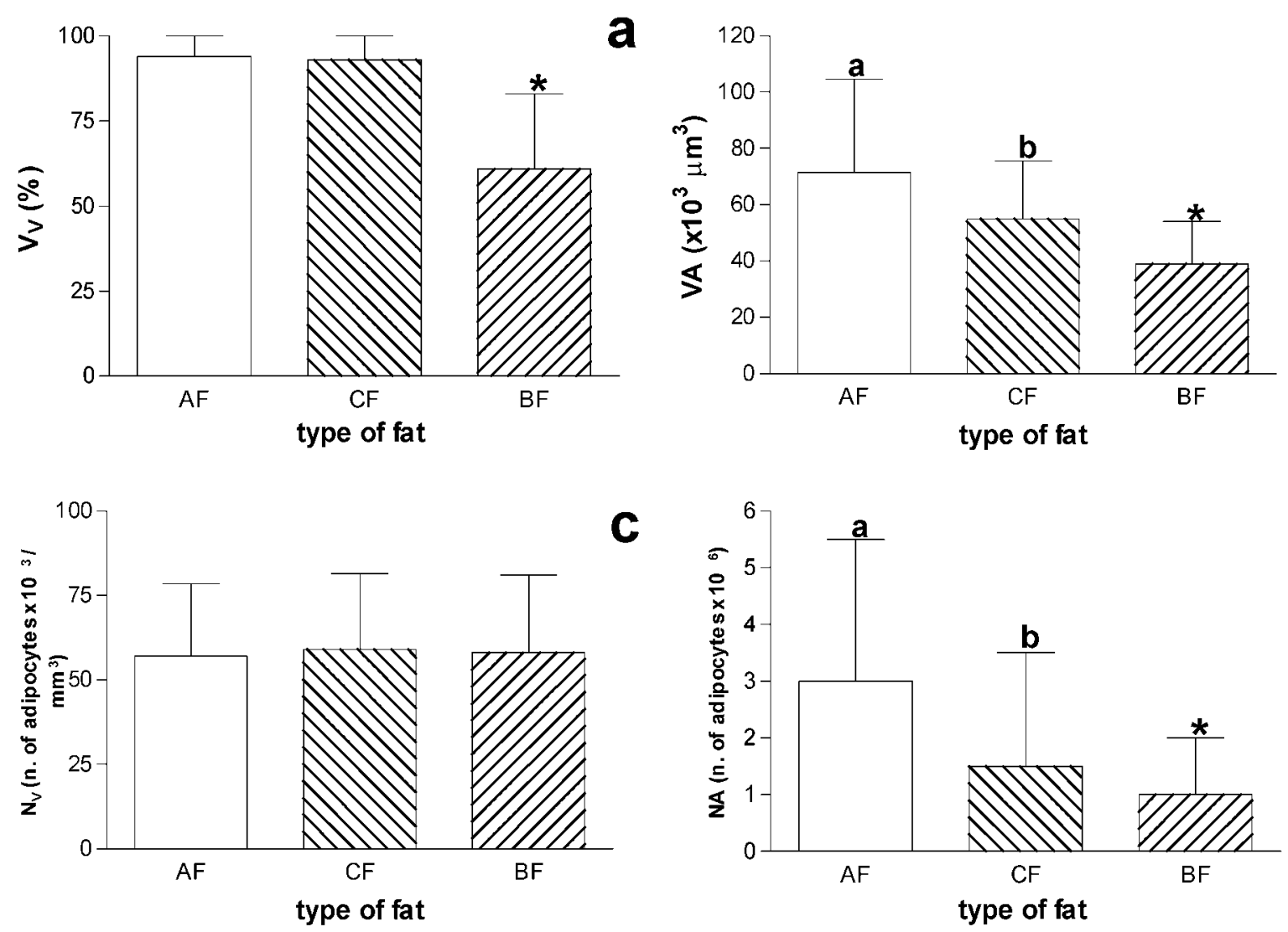

Fig. 2. Bar graphs indicating the stereological parameters in aspirated fat $(A F)$, centrifuged fat (CF) and biopsied fat $(B F)($ mean $\pm S D)$. a. Volume fraction of adipocytes in the fat tissue $\left(V_{V}\right)$. b. Mean cell volume of the adipocytes (VA). c. Numerical density of adipocytes in the fat tissue $\left(N_{V}\right) . d$. Absolute number of adipocytes in the fat tissue (NA). Different alphabetical superscripts show statistically significant differences between AF and $C F$. An asterisk shows statistically significant differences between $C F$ and BF $(p<0.05)$.

proportional to the injected volume: therefore, the over-correction by many authors (Bircoll and Novack, 1987) makes no sense. FAG survival would be better increased with repeated treatment sessions rather than with over-corrections in a single session (Coleman, 1995; 1997). This fact may restrict FAG indications to the refilling of small or mild facial contour defects while fat flaps and other filling materials are preferred for reconstructing severe subcutaneous soft tissue deplections.

\section{CONCLUSIONS}

1. The fat autografts partially survive in two-thirds of the injected volume at the 14- month follow-up.
This survival represents a successful but incomplete and temporary clinical result for patients with facial soft tissue defects.

2. The first application of stereology to the quantitation of grafts survival in plastic surgery has been successfully achieved. Stereological analysis was a reliable method for quantifying fat autograft survival.

In routine practice, it would be enough to quantify the volume fraction of adipocytes in the injected and the biopsied fat to know the VSF. Although a limitation to biopsy exists, the stereological method would enable the standardized comparison between different series and authors in a more accurate way than clinical photographs and 2-dimensional methods. 


\section{REFERENCES}

American Society of Plast Reconstr Surg 1998, http:// www.plasticsurgery.org.

Assadi M, Haramis HT (1993). Successful autologous fat injection at 5-year follow-up. Plast Reconstr Surg 91: 755-5.

Bircoll M (1987). Fat autografting. Plast Reconstr Surg 1987;80:647-7.

Bircoll M, Novack BH (1987). Autologous fat transplantation employing liposuction techniques. Ann Plast Surg 18: 327-9.

Billings E Jr., May JW Jr. (1989). Historical review and present status of free fat graft autotrasplantation in plastic and reconstructive surgery. Plast Recosntr Surg 83:368-81.

Boyce RG, Nuss WD, Kluka AE (1994). The use of autogenous fat, fascia and nonvascularized muscle grafts in the head and neck. In: Otolaryngologic clinics of North America. Soft tissue augmentation and reconstruction in the head and neck, 39-68.

Carpaneda CA, Ribeiro MT (1994). Percentage of graft viability versus injected volume in adipose autotrasplants. Aesth Plast Surg 18:17-19.

Castro Ferreira M (2003). What are we doing and where are we going?. Aesth Plast Surg 27:5-5.

Chajchir A, Benzaquen I (1989). Fat-grafting injection for soft tissue augmentation. Plast Reconstr Surg 84:921-34.

Coleman SR (1995). Long-term survival of fat trasplants: controlled demonstrations. Aesthetic Plast Surg 19:421-5.

Coleman SR (1997). Facial recontouring with lipostructure. Clinics in Plastic Surgery 24:347-67.

Cruz-Orive LM (1987). Particle number can be estimated using a disector of unknown thickness: the selector. J Microsc 145:121-42.

Ellenbogen R (2000). Fat transfer: Current use in practice. Clin Plast Surg 27:545-56.

Ersek RA, Chang P, Salisbury MA (1998). Lipolayering of autologous fat: An improved technique with promising results. Plast Reconstr Surg 101:820-7.

Goldwyn RM (1988). Unproven treatment. Whose benefit? Whose responsibility? (editorial). Plast Reconstr Surg 81:946-7.

Gormley DE, Eremia S (1990). Quantitative assessment of augmentation therapy. J Dermatol Surg Oncol 16: 1147-51.

Grazer TJ, Klingbeil JR (1980). Body Image: A surgical perspective. St. Louis: Mosby.

Guerrerosantos J (2000). Long-term outcome of autologous fat transplantation in Aesthetic Facial Recontouring: sixteen years of experience with 1936 cases. Clin Plast Surg 27:515-44.

Gundersen HJ, Jensen EB (1985). Stereological stimation of the volume-weight mean volume of arbitrary particles observed on random sections. J Microsc 138:127-42.
Gundersen HJG (1986). Stereology of arbitrary particles. A review of unbiased number and size estimations and the presentation of some new ones in memory of William R. Thompson. J Microsc 143:3-45.

Gundersen HJG, Jensen EB (1987). The efficiency of systematic sampling in stereology and its prediction. $\mathrm{J}$ Microsc 147:229-63.

Gundersen HBG, Bagger P, Bendtsen TF (1988). The new stereological tools: disector, fraccionator, nucleator and point sampled intercepts and their use in pathological research and diagnosis. Acta Pathol Microbiol Immunol Scand 96:857-81.

Horl HW, Séller AM, Bierner E (1991). Technique for liposuction fat reimplantation and long term volume evaluation by magnetic resonance imaging. Ann Plast Surg 26:248-58.

Jensen EB, Sundberg R (1986). Generalized associated point methods or sampling planar objects. J Microsc 144:5570.

Klein JA (1987). The tumescent technique for liposuction surgery. Am J Cosmetic Surg 4:263-3.

Kononas TC, Bucky LP, Hurley C, May JW Jr (1993). The fat of suctioned and surgically removed fat after reimplantation for soft tissue augmentation: a volumetric and histologic study in the rabbit. Plast Reconstr Surg 91:763-8.

Matsudo PK, Toledo LS (1988). Experience of injected fat grafting. Aesthetic Plast Surg 12:35-8.

May JW Jr (1990): Comparative study of survival autologous adipose tissue taken and transplanted by different techniques (Discussion). Plast Reconstr Surg 85:387-7.

Mayhew TM, Gundersen HJG (1996). "If you assume, you can make an ass out of you and me": a decade of disector for stereologic counting of particles in the $3 \mathrm{D}$ space. J Anat 188:1-15.

Mc Carthy JG (1990). Introduction to Plastic Surgery. Plastic Surgery, Philadelphia: WB Saunders, 1:1-24.

Mendis-Handagama SMLC (1992). Estimation error of Leydig cell numbers in atrophied rat testes due to the assumption of spherical nuclei. J Microsc 168:25-32.

Miles RE (1978). The sampling by quadrants of a planar agregates. J Microsc 113:257-67.

Neuber F (1893). Fettransplantation. Bericht über die Verhandlungen der Dt Ges Chir. Zentralbl Chir 22:66-6.

Nguyen A, Pasyk KA, Bouvier TN, Hasset CA, Argenta LC (1990). Comparative study of survival of autologous adipose tissue taken and transplanted by different techniques. Plast Reconstr Surg 85:378-86.

Niechajevia I, Sevcuk O (1994). Long term results of fat transplantation: Clinical and histologic studies. Plast Reconstr Surg 94:496-506.

Peer LA, Walker JC (1951). The behavior of autogenous human tissue grafts II. Plast Reconstr Surg 7:73-84. 
Pinski KS, Roenigk HH Jr (1992). Autologous fat transplantation: Long-term follow-up. J Dermatol Surg Oncol 18:179-84.

Smahel J (1986). Adipose tissue in plastic surgery. Ann Plast Surg 16:444-53.

Sterio DC (1984). The unbiased estimation of number and sizes of arbitrary particles using the disector. J Microsc 134:127-36.

Von Heimburg D, Pallua N (2001): Two-year histological outcome of facial lipofilling. Ann Plast Surg 46:644-6.

Wilkinson TS (1994). Fat grafting. In: Practical procedures in Aesthetic Plastic Surgery. New York: Springer-Velag. 